\title{
Sistem Pakar Diagnosa Penyakit THT dengan Metode Inner Product dan Certainty Factor
}

\author{
Lady Silk $\mathbf{M}^{1}$, Retno Purwanig Tiyas ${ }^{2}$ \\ 1,2) Politeknik Penerbangan Surabaya \\ Jl. Jemur Andayani I/73, Surabaya 60236 \\ Email : lady.silk@poltekbangsby.ac.id
}

\begin{abstract}
ABSTRAK
Sistem pakar (expert sistem) adalah sistem yang berusaha mengadopsi pengetahuan manusia ke komputer, agar komputer dapat menyelesaikan masalah seperti layaknya para pakar (expert). Banyaknya masyarakat yang terkena penyakit THT dan minimnya jumlah spesialis THT mengakibatkan spesialis THT kesulitan menangani jumlah pasien yang banyak. Untuk menyelesaikan masalah tersebut salah satunya dengan membuat sistem pakar diagnosa penyakit THT. Sistem pakar diagnosa penyakit THT dapat membantu pakar sebagai asisten yang handal dengan tujuan membantu pasien agar tetap dapat berobat meskipun pakar tidak ada di tempat. Sistem pakar ini tentunya dapat menyelesaikan suatu permasalahan tentang THT dengan meniru cara kerja dokter spesialis THT.

Motode inner product digunakan untuk diagnosa awal dengan masukan gejala pasien. Hasil dari proses inner product diambil nilai tertinggi sebagai keluaran yang berupa nama penyakit dan jenis pengobatan pasien. Jika nilai tertinggi yang dihasilkan dari proses inner product lebih dari satu dan gejala penyakit mempunyai nilai kuantitas dan waktu, maka akan dilanjutkan ke diagnosa lanjut menggunakan metode certainty factor, dengan masukan lama waktu masing-masing gejala, atau kuantitas gejala untuk mengetahui nilai keyakinan terhadap suatu penyakit berdasarkan lama waktu masing-masing gejala dan kuantitas gejala tersebut.
\end{abstract}

Kata Kunci : Sistem pakar, THT, diagnosa, inner product, certainty factor

\section{PENDAHULUAN}

Sistem pakar (expert sistem) adalah sistem yang berusaha mengadopsi pengetahuan manusia ke komputer, agar komputer dapat menyelesaikan masalah seperti layaknya para pakar (expert). Banyaknya masyarakat yang terkena penyakit THT dan minimnya jumlah spesialis THT mengakibatkan spesialis THT kesulitan menangani jumlah pasien yang banyak. Untuk menyelesaikan masalah tersebut salah satunya dengan membuat sistem pakar diagnosa penyakit THT. Sistem pakar diagnosa penyakit THT dapat membantu pakar sebagai asisten yang handal dengan tujuan membantu pasien agar tetap dapat berobat meskipun pakar tidak ada di tempat. Sistem pakar ini tentunya dapat menyelesaikan suatu permasalahan tentang THT dengan meniru cara kerja dokter spesialis THT.

Dalam melakukan diagnosa, seorang pakar terkadang berdasarkan pada data yang kurang lengkap atau data yang tidak pasti. Sistem dapat mendiagnosa penyakit pasien dengan tepat menggunakan inner product. Agar sistem pakar dapat melakukan penalaran sebagaimana seorang pakar meskipun data yang diperoleh kurang lengkap atau kurang pasti dilanjutkan dengan Certainty Factor $^{[2]}$. Motode inner product digunakan untuk diagnosa awal dengan masukan gejala pasien. Hasil dari proses inner product diambil nilai tertinggi sebagai keluaran yang berupa nama penyakit dan jenis pengobatan pasien. Jika nilai tertinggi yang dihasilkan dari proses inner product lebih dari satu dan gejala penyakit mempunyai nilai kuantitas dan waktu maka akan dilanjutkan ke diagnosa lanjut menggunakan metode 
certainty factor, dengan masukan lama waktu masing-masing gejala atau kuantitas gejala untuk mengetahui nilai keyakinan terhadap suatu penyakit berdasarkan lama waktu masingmasing gejala dan kuantitas gejala tersebut.

\section{METODE PENELITIAN}

\section{Metode Inner Product}

Inner product adalah perkalian vector dengan cara mengalikan titik-titik antar vektor, jadi hasilnya berupa skalar. Bila dibiarkan semua elemen salah satu vektor tersebut berupa nilai ' 1 ', maka kita akan memperoleh penjumlahan semua elemen vektor lainnya ${ }^{[7]}$.

Rumus dasar inner product terdapat pada persamaan 1 :

$\sum_{i=1}^{n} a_{i} b_{i}=a_{1} b_{1}+a_{2} b_{2}+\cdots+a_{n} b_{n}$

Keterangan:

$a=$ vector a (gejala pasien)

$b=$ vector $\mathrm{b}$ (gejala pada rule penyakit)

$n=$ banyak gejala

Untuk membuat aplikasi yang sesuai dengan model permasalahan dokter dalam menentukan penyakit yang diderita oleh pasien, salah satunya dengan metode inner product, yaitu pengambilan satu nilai tertinggi suatu penyakit dari berbagai banyak nilai yang lain, dimana nilai tertinggi tersebut diambil setelah proses perhitungan gejala dengan penyakit ${ }^{[7]}$.

\section{Metode Certainty factor}

Faktor kepastian (certainty factor) diperkenalkan oleh Shortliffe Buchanan dalam pembuatan MYCIN. Certainty factor (CF) merupakan nilai parameter klinis yang diberikan MYCIN untuk menunjukkan besarnya kepercayaan ${ }^{[2]}$. Certainty factor menunjukkan ukuran kepastian terhadap suatu fakta atau aturan. Notasi factor kepastian ${ }^{[8]}$ :

$C F[h, e]=M B[h, e]-M D[h, e]$

Dengan:

$C F[h, e] \quad=$ factor kepastian

$M B[h, e]=$ ukuran kepercayaan terhadap hipotesis $\mathrm{h}$, jika diberikan evidence $\mathrm{e}$ (antara 0 dan 1)

$M D[h, e]=$ ukuran ketidakpercayaan terhadap hepotesis $\mathrm{h}, \mathrm{jika}$ diberikan evidence $\mathrm{e}$ (antara 0 dan 1)

Agar sistem pakar dapat melakukan penalaran sebagaimana seorang pakar meskipun data yang diperoleh kurang lengkap atau kurang pasti, dapat digunakan certainty factor. Kebanyakan sistem pakar yang ada, untuk mendapatkan kepercayaan pengguna terhadap gejala yang ada (misalnya batuk) adalah dengan meminta nilai CF langsung dari pasien. Menurut peneliti, hal ini sulit diperoleh mengingat pasien sendiri sulit memperkirakan berapa derajat kebatukannya. Untuk mengetahui derajat kepercayaan pengguna terhadap gejala yang dialami, yaitu dengan kuantifikasi pertanyaan. Yang dimaksud dengan kuantifikasi pertanyaan disini yaitu pemberian faktor kuantitas dan lama pada gejala. Pengguna diminta untuk menentukan kuantitas gejala dan lama gejala yang dialami, setelah itu sistem akan menghitung nilai certainty factor dengan menggunakan derajat keanggotaan kuantitas dan gejala tersebut terhadap nilai dalam aturan. Aturan yang mengandung fungsi kuantitas dan waktu, maka $\mathrm{CF}$ akan dihitung sebesar gabungan derajat keanggotaan dari fungsi karakteristik kuantitas dan derajat keanggotaan dari fungsi karakteristik waktu ${ }^{[2]}$.

Untuk fungsi karakteristik kuantitas didasarkan pada bagian aturan operator kuantitas yaitu Kuantitas dan toleransi kuantitas. Sedangkan fungsi karakteristik waktu didasarkan pada aturan operator waktu yaitu waktu dan toleransi waktu. Operator kuantitas dan operator 
waktu yang disediakan berupa "=", " $>=$ ", dan " $<=$ ". Kuantitas dan waktu merupakan syarat nilai dari berlakunya aturan itu, sedangkan toleransi kuantitas dan toleransi waktu memberikan batasan hingga suatu nilai yang membuat data premis ini tidak diabaikan. Sesuai dengan jenis operatornya, ada tiga macam fungsi karakteristik untuk kuantitas dan waktu.

\section{Grafik dan Persamaan fungsi operator "="}

$C F(x)=\left\{\begin{array}{c}=0, j i k a\{(x \leq(\text { Nilai }- \text { Toleransi })) \text { atau }(x \geq(\text { Nilai }+ \text { Toleransi }))\} \\ =-\left(\frac{\text { Nilai }+ \text { Toleransi }}{\text { Toleransi }}\right), \text { jika Nilai }- \text { Toleransi }<x<\text { Nilai } \\ =\left(\frac{\text { Nilai }+ \text { Toleransi }-x}{\text { Toleransi }}\right), \text { jika Nilai }<x<\text { Nilai }+ \text { Toleransi } \\ =1 \text { jika } x=\text { Nilai }\end{array}\right\}$

Dengan:

$x=$ Waktu / kuantitas gejala yang dialami pasien

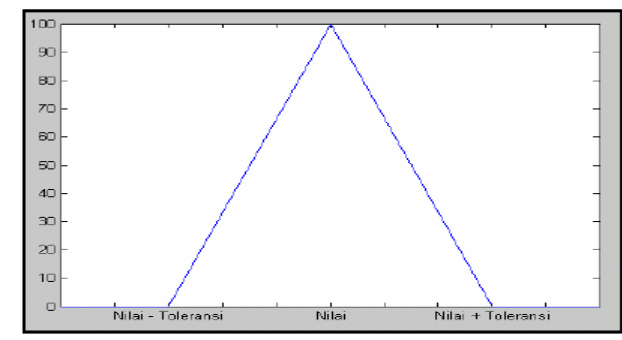

Gambar 1 Grafik Fungsi Operator "="

Nilai $\quad=$ Nilai kuantitas/Waktu standar

Toleransi $=$ Toleransi waktu/kuantitas

\section{Grafik dan Persamaan fungsi operator " $\geq$ "}

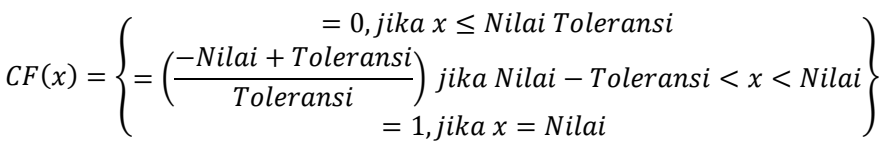

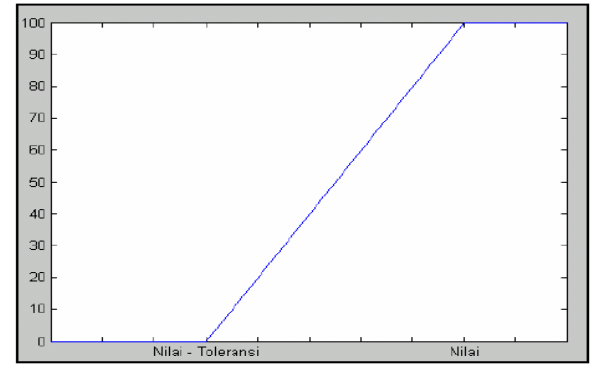

Gambar 2 Grafik Fungsi Operator " $\geq$ "

\section{Grafik dan Persamaan fungsi operator " $="$}

$C F(x)=\left\{\begin{array}{cl}=0, j i k a x & \text { Nilai }+ \text { Toleransi } \\ =\left(\frac{\text { Nilai }+ \text { Toleransi }-x}{\text { Toleransi }}\right), & \text { jika Nilai }<x<\text { Nilai }+ \text { Toleransi } \\ =1, \quad \text { jika } x<\text { Nilai }\end{array}\right\}$

CFUser $=\operatorname{Min}(C F \operatorname{Kuantitas}(x), C F W a k t u(x))^{[2]}$.

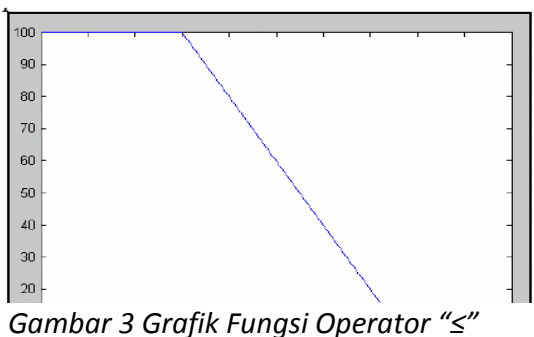

\section{Kombinasi aturan:}

Berikut Persamaan yang digunakan dalam kombinasi certainty factor.

$$
\begin{aligned}
& C F(x \text { Dan } y)=\operatorname{Min}(C F(x), C F(y)) \\
& C F(x \text { Atau } y)=\operatorname{Max}(C F(x), C F(y)) \\
& C F(\operatorname{Tidak} x)=-C F(x)
\end{aligned}
$$

\section{CF Konklusi}

CFKonklusi $=$ CFHasil $\times 1 \times 100 \%$

Istilah-istilah besarnya CF konklusi atau Kesimpulan seperti tabel 2.1 
Tabel Istilah-istilah besarnya CF kunklusi

\begin{tabular}{|l|l|}
\hline \multicolumn{1}{|c|}{ Istilah } & \multicolumn{1}{c|}{ Nilai CF } \\
\hline Tidak Tahu & $0 \leq \mathrm{CF}<0,2$ \\
\hline Mungkin & $0,2 \leq \mathrm{CF}<0,4$ \\
\hline Kemungkinan Besar & $0,4 \leq \mathrm{CF}<0,6$ \\
\hline Hampir Pasti & $0,6 \leq \mathrm{CF}<0,8$ \\
\hline Pasti & $0,8 \leq \mathrm{CF} \leq 1$ \\
\hline
\end{tabular}

\section{HASIL PEMBAHASAN}

Aplikasi ini dapat membantu Sistem Pakar dalam mendiagnosa penyakit THT dengan metode Inner product dan Certainty factor agar didapatkan diagnosa yang sesuai dengan gejala dan pemeriksaan fisik, dan dapat diketahui pengobatannya.

User memasukkan nama pasien dan gejala-gejala yang dialami oleh pasien yang sebelumnya sudah dilakukan pemeriksaan fisik. Karena dalam menentukan gejala pasien tidak hanya dengan menanyakan langsung kepada pasien tetapi harus didahului dengan pemeriksaan fisik yang dilakukan oleh suster supaya data gejala pasien yang akan diproses oleh sistem lebih akurat.

Adapun kebutuhan fungsional yang harus dipenuhi aplikasi sistem pakar diagnosa penyakit THT dengan metode Inner product dan Certainty factor ini adalah :

a. Nama-nama penyakit THT dapat diupdate.

b. Nama-nama gejala penyakit THT dapat diupdate

c. Penentuan penyakit yang sesuai dengan gejala dapat diupdate

d. Solusi pengobatan serta dapat diupdate berdasarkan expert (orang yang ahli dibidangnya).

\section{Desain Basis Data}

\section{Physical Data Model (PDM)}

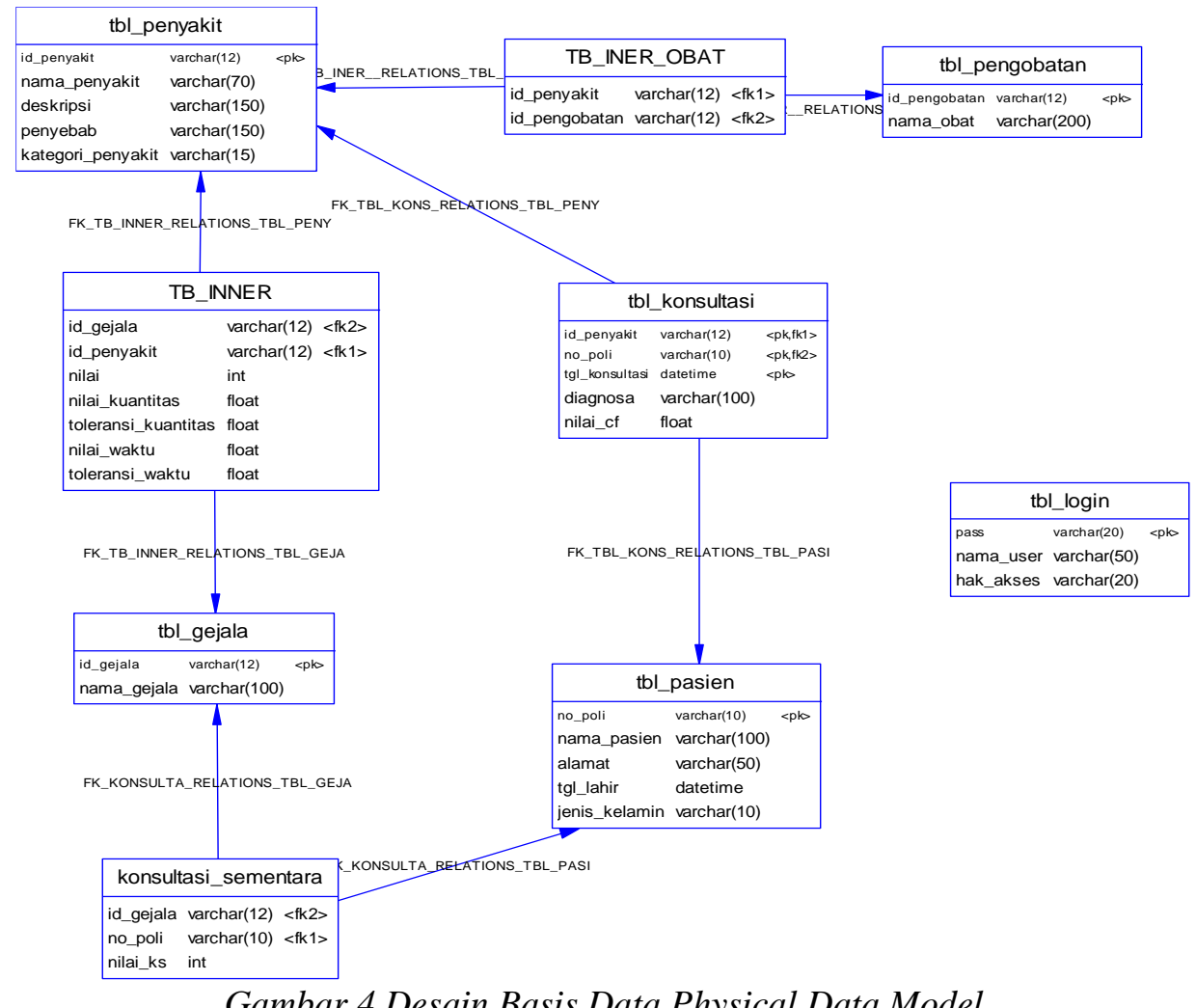

Gambar 4 Desain Basis Data Physical Data Model 


\section{Rancangan Metode Inner Product}

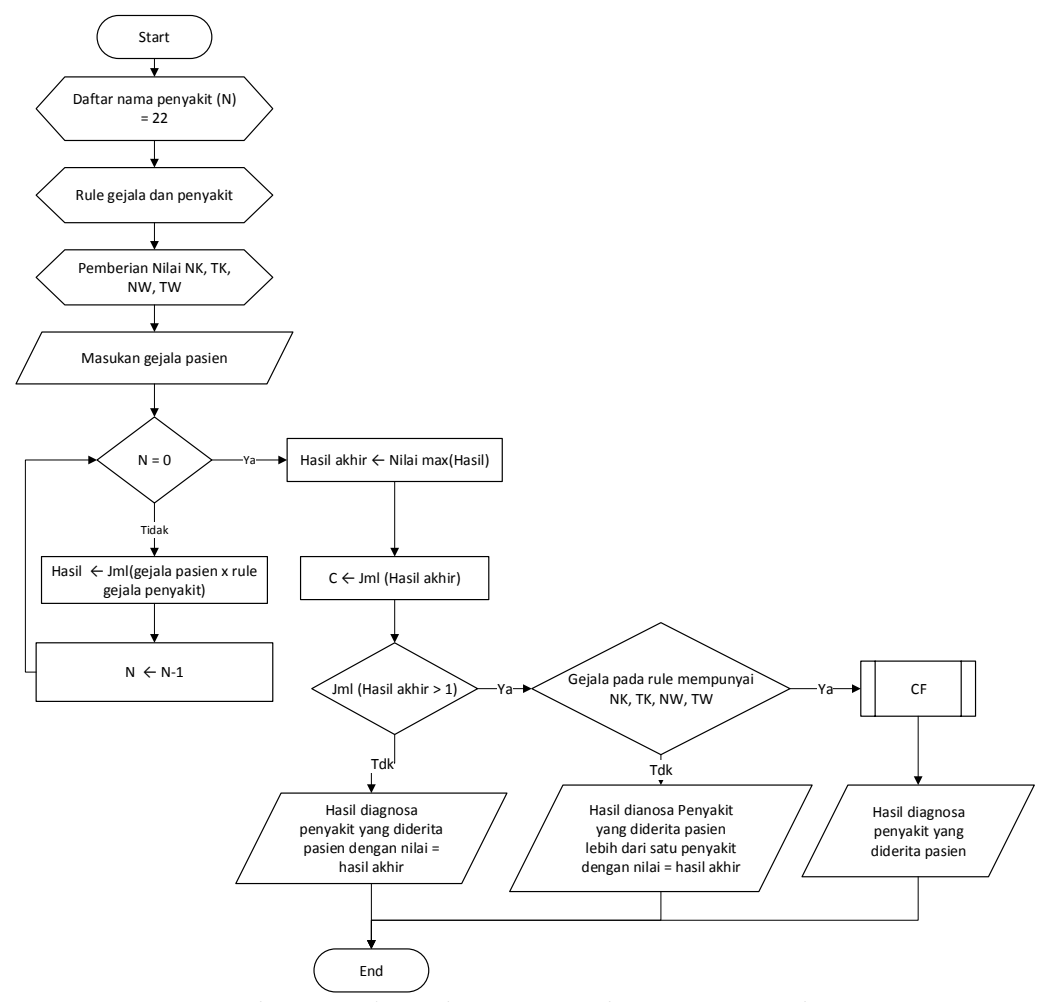

Gambar 5 Flowchart Metode Inner Product

\section{Penerapan Metode Inner Product pada Sistem}

Berikut langkah-langkah melakukan konsultasi dengan menerapkan metode inner product:

1. Melakukan pendaftaran pasien baru.

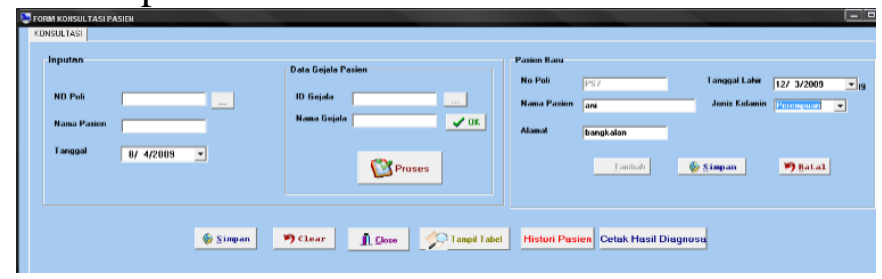

Gambar 6 Form pendaftaran pasien pada form konsultasi

2. Mengisi data pasien yang konsultasi.

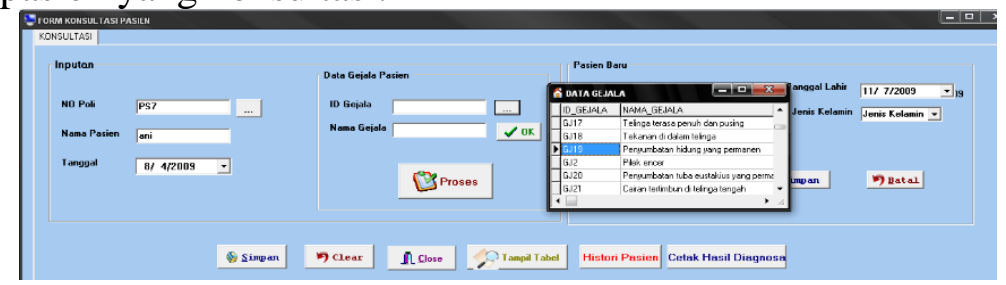

Gambar 7 Form Memasukan Data Pasien Dan Gejala Pasien Pada Form Konsultasi

3. Setelah gejala-gejala pasien dipilih maka sistem akan memproses gejala-gejala tersebut dengan metode inner product sampai menghasilkan nilai tertinggi sebagai keluarannya yang berupa nama penyakit. Setelah pasien terdiagnosa penyakit tertentu maka akan muncul solusi pengobatan pasien 


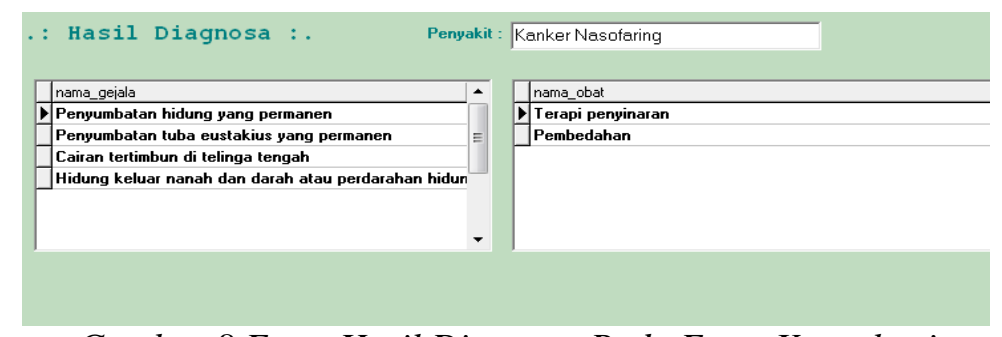

Gambar 8 Form Hasil Diagnosa Pada Form Konsultasi

\section{Flowchart Metode Certainty Factor}

Flowchart untuk proses diagnosa lanjut dengan Metode Certainty Factor yang menggunakan kuantifikasi pertanyaan.

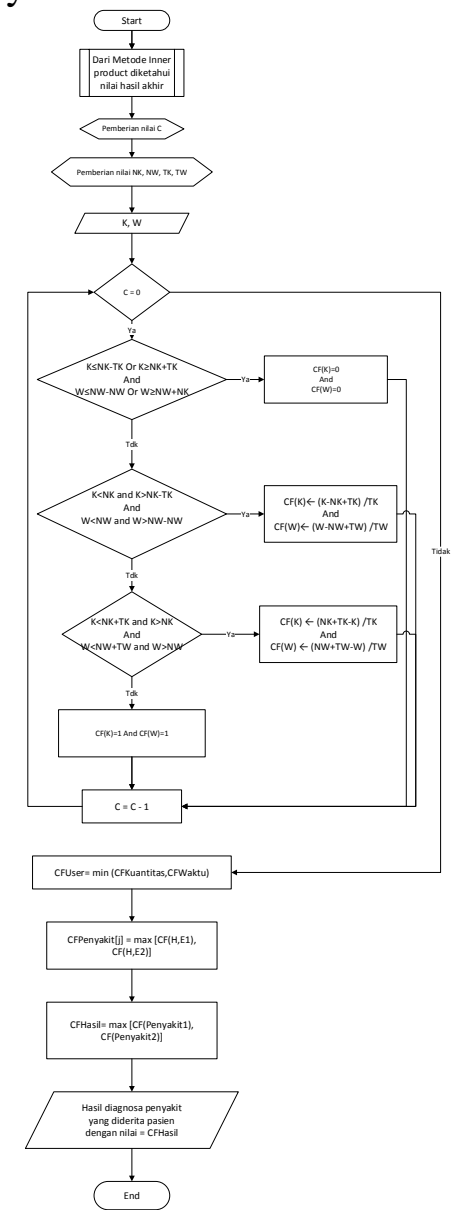

Gambar 9 Flowchart Metode Certainty Factor

Penerapan Metode Certainty Factor dengan Kuantifikasi Pertanyaan pada Sistem

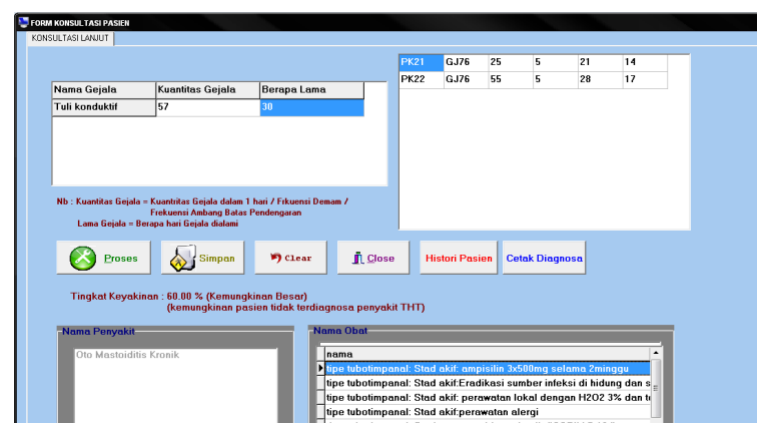

Gambar 10 Form Konsultasi Dengan Metode Certainty Factor 


\section{Perhitungan Manual Metode Inner Product Sampai Metode Certainty factor}

Studi kasus:

Misalkan ada seorang pasian yang bertama Ani menderita penyakit THT. Setelah diperiksa oleh suster ternyata gejala dan hasil pemeriksaan Ani adalah tuli konduktif dengan penurunan pendengaran $57 \mathrm{~dB}$ selama 30 hari

Penyelesaian:

Berdasarkan Tabel Gejala Penyakit maka gejala dan hasil pemeriksaan tersebut bernilai 000000000000000000000000000000000000000000000000000000000000000000000000000 0100

Kemudian nilai tersebut dikalikan dengan nilai Rule Gejala terhadap Penyakit.

1. Proses Inner product (diagnosa pertama) menggunakan persamaan 1

$$
\sum_{i=1}^{n} a_{i} b_{i}=a_{1} b_{1}+a_{2} b_{2}+\cdots+a_{n} b_{n}
$$

A. 000000000000000000000000000000000000000000000000000000000000000000000 0000000100X111000000000000000000000000000000000000000000000000000000 000000000000000000000

$=0+0+0+0+0+0+0+0+0+0+0+0+0+0+0+0+0+0+0+0+0+0+0+0+0+0+0+0+0+0+0+0+$ $0+0+0+0+0+0+0+0+0+0+0+0+0+0+0+0+0+0+0+0+0+0+0+0+0+0+0+0+0+0+0+0+0$ $+0+0+0+0+0+0+0+0+0+0+0+0+0+0=0$

B. 000000000000000000000000000000000000000000000000000000000000000000000 0000000100X000111100000000000000000000000000000000000000000000000000 $000000000000000000000=0$

C. 000000000000000000000000000000000000000000000000000000000000000000000 0000000100X000000011100000000000000000000000000000000000000000000000 $000000000000000000000=0$

D. 000000000000000000000000000000000000000000000000000000000000000000000 0000000100X000000000011110000000000000000000000000000000000000000000 $000000000000000000000=0$

E. 000000000000000000000000000000000000000000000000000000000000000000000 0000000100X000000000000001111000000000000000000000000000000000000000 $000000000000000000000=0$

F. 000000000000000000000000000000000000000000000000000000000000000000000 000000100X0000000000000000001111000000000000000000000000000000000000 $00000000000000000000=0$

G. $\quad 000000000000000000000000000000000000000000000000000000000000000000000$ 0000000100X000000000000000000000011000000000000000000000000000000000 $000000000000000000000=0$

H. 000000000000000000000000000000000000000000000000000000000000000000000 0000000100X000000000000000000000000111100000000000000000000000000000 $000000000000000000000=0$

I. 000000000000000000000000000000000000000000000000000000000000000000000 0000000100X000000000000000000000000000011000000000000000000000000000 $000000000000000000000=0$

J. $\quad 000000000000000000000000000000000000000000000000000000000000000000000$ 0000000100X000000000000000000000000000000110000000000000000000000000 $000000000000000000000=0$

K. 000000000000000000000000000000000000000000000000000000000000000000000 0000000100X000000000000000000000000000000001100000000000000000000000 $000000000000000000000=0$ 
L. $\quad 000000000000000000000000000000000000000000000000000000000000000000000$ 0000000100X000000000000000000000000000000000011100000000000000000000 $0000000000000000000=0$

M. 000000000000000000000000000000000000000000000000000000000000000000000 0000000100X000000000000000000000000000000000000111111000000000000000 $000000000000000000000=0$

N. 000000000000000000000000000000000000000000000000000000000000000000000 0000000100X000000000000000000000000000000000000000000011111000000000 $000000000000000000000=0$

o. 000000000000000000000000000000000000000000000000000000000000000000000 0000000100X000000000000000000000000000000000000000000000000111100000 $000000000000000000000=0$

P. $\quad 000000000000000000000000000000000000000000000000000000000000000000000$ 0000000100X000000000000000000000000000000000000000000000000000111111 $000000000000000000000=0$

Q. $\quad 000000000000000000000000000000000000000000000000000000000000000000000$ 0000000100X000000000000000000000000000000000000000000000000000100000 $111110000000000000000=0$

R. 000000000000000000000000000000000000000000000000000000000000000000000 0000000100X000000000000000000000000000000000000000000000000000000000 $010111110000000000000=0$

s. 000000000000000000000000000000000000000000000000000000000000000000000 0000000100X000000000000000000000000000000000000000000000000000000000 $010001001000000000000=0$

T. 000000000000000000000000000000000000000000000000000000000000000000000 0000000100X000000000000000000000000000000000000000000000000000000000 $001000001111100000000=0$

U. 000000000000000000000000000000000000000000000000000000000000000000000 0000000100X000000000000000000000000000000000000000000000000000000000 $000000000000011111100=1$

v. 000000000000000000000000000000000000000000000000000000000000000000000 0000000100X000000000000000000000000000000000000000000000000000000000 $000000000000000000101=1$

Hasil perhitungan

Gejala pasien terhadap Penyakit $A=0, B=0, C 3=0, D=0, E=0, F=0, G=0, H=0, I=0, J=0$, $\mathrm{K}=0, \mathrm{~L}=0, \mathrm{M}=0, \mathrm{~N}=0, \mathrm{O}=0, \mathrm{P}=0, \mathrm{Q}=0, \mathrm{R}=0, \mathrm{~S}=0, \mathrm{~T}=0, \mathrm{U}=1, \mathrm{~V}=1$.

Jadi nilai tertingginya adalah 1 dengan jumlah dua penyakit yaitu penyakit $\mathrm{U}$ dan $\mathrm{V}=$ Otitis eksternal difusa dan oto mastoiditis kronis (sesuai Tabel Lampiran II). Karena hasil diagnosa yang pertama keluar dua penyakit Otitis eksternal difusa dan oto mastoiditis kronis maka dilanjutkan diagnosa yang kedua agar penyakit yang diderita pasien lebih spesifik

2. Perhitungan certainty factor (Diagnosa ke dua)

Dari hasil diagnosa pertama pasien terdiagnosa Otitis eksternal difusa dan oto mastoiditis kronis.

berdasarkan gejala tuli konduktif dengan penurunan pendengaran $57 \mathrm{~dB}$ selama 30 hari maka dapat dihitung penyakit yang lebih dominan dimana diambil tingkat keyakinan terbesar. Persamaan yang digunakan adalah persamaan 3. 


$$
C F(x)=\left\{\begin{array}{c}
=0, j i k a\{(x \leq(\text { Nilai }- \text { Toleransi })) \text { atau }(x \geq(\text { Nilai }+ \text { Toleransi }))\} \\
=-\left(\frac{\text { Nilai }+ \text { Toleransi }}{\text { Toleransi }}\right), \text { jika Nilai }- \text { Toleransi }<x<\text { Nilai } \\
=\left(\frac{\text { Nilai }+ \text { Toleransi }-x}{\text { Toleransi }}\right), \text { jika Nilai }<x<\text { Nilai }+ \text { Toleransi } \\
=1 \text { jika } x=\text { Nilai }
\end{array}\right\}
$$

Diketahui rule penyakit terhadap gejala:

Otitis eksternal difusa :

NKTuliKonduktif $\quad=25 \mathrm{~dB}$

TKTuliKonduktif $\quad=5 \mathrm{~dB}$

NWTuliKonduktif $=21$ hari

TWTuliKonduktif $=14$ hari

Oto mastoiditis kronis :

NKTuliKonduktif $\quad=55 \mathrm{~dB}$

TKTuliKonduktif $\quad=5 \mathrm{~dB}$

NWTuliKonduktif $=28$ hari

TWTuliKonduktif $\quad=17$ hari

Berdasarkan Rule Penyakit dan Gejala, serta Gejala yang dialami pasien maka didapat

CFKuantitas OtitisEksternalDifusa (TuliKonduktif) $=0$

FKWaktuOtitisEksternalDifusa(TuliKonduktif) $=(21+14-30) / 14 \quad=0,357$

CFKuantitas OtoMastoiditisKronis (TuliKonduktif) $=(55+5-57) / 5 \quad=0,6$

CFKWaktuOtoMastoiditisKronis(TuliKonduktif) $=(28+17-30) / 17=0.75$

Hasil

CFUOtitisEksternalDifusa (TuliKonduktif) $=$

= Min (CFKuantitas OtitisEksternalDifusa, CFWaktu OtitisEksternalDifusa)

$=\operatorname{Min}(0 ; 0,357)=0$

CFUOtoMastoiditisKronis $($ TuliKonduktif $)=$

= Min (CFKuantitas OtoMastoiditisKronis, CFWaktu OtoMastoiditisKronis)

$=\operatorname{Min}(0,6 ; 0,75)=0,6$

CFHasil

$=$ Max (CFUOtitisEksternalDifusa, CFUOtoMastoiditisKronis)

$=\operatorname{Max}(0 ; 0,6)$

$=0,0$

= OtoMastoiditisKronis

CFKonklusi

$=$ CFHasil $1 \times 100 \%$

$=0,6 \times 1 \times 100$

$=60 \%=$ Kemungkinan Besar

Jadi pasien dengan gejala tuli konduktif dengan penurunan pendengaran 50dB dalam waktu

30 hari hampir kemungkinan besar terdiagnosa Oto Mastoiditis Kronis

\section{Implementasi Menambah Rule Penyakit}

Form Menambah Rule Penyakit untuk Metode Inner product

Untuk menambah rule penyakit dengan Metode Inner product pada Tab Rule Penyakit pada Form Utama. 


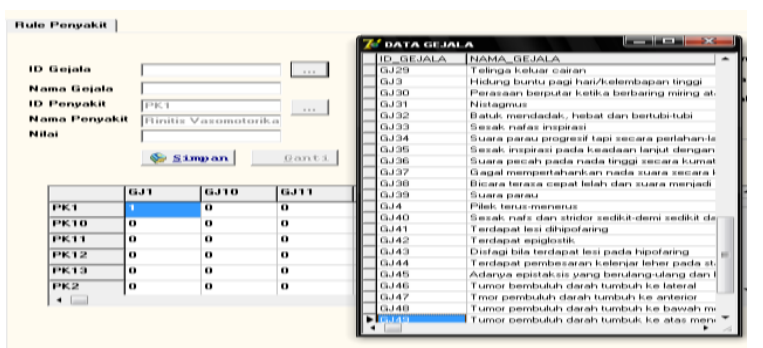

Gambar 11 Form menambah rule penyakit dengan Metode Inner product

\section{Form Menambah Rule Penyakit untuk Metode Certainty factor}

Untuk menambah rule penyakit dengan Metode Certainty factor, Gejala yang mempunyai nilai kuantitas harus diisi lengkap.

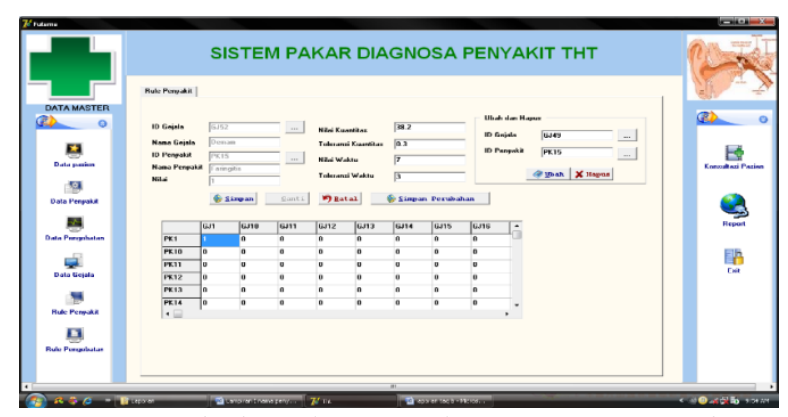

Gambar 12 Form Menambah Rule Penyakit Dengan Metode Certainty Factor

\section{KESIMPULAN}

Kombinasi metode inner product dan certainty factor dapat digunakan pada sistem pakar diagnosa penyakit THT ini dengan keluaran berupa penyakit yang diderita pasien berdasarkan gelaja-gejala penyakit pasien. Sistem ini dapat memudahkan dokter spesialis THT dalam menanggani pasiennya karena sistem ini dapat juga digunakan oleh asisten dokter atau suster sehingga tidak menunggu keberadaan dokter saat mendiagnosa pasien.

Sistem pakar ini bersifat dinamis sehingga apabila ada rule penyakit dan gejala baru sistem tetap dapat bekerja.

\section{DAFTAR PUSTAKA}

[1] Amrullah, C. Diagnosa Penyakit THT dengan Metode Fuzzy Logic. Tugas Akhir tidak Terpublikasi. Bangkalan:Universitas Trunojoyo. 2007.

[2] Kusrini. Kuantifikasi Pertanyaan untuk Mendapatkan Certainty Factor Pengguna pada Aplikasi Sistem Pakar untuk Diagnosis Penyakit. 2006. Tersedia dalam <http://www.computerforhumanity.blogspot.com/2008/05/metode_kuantifikasi_pertanyaan_untuk .html> Diakses 31 Maret 2009. 